\title{
KANCELARIJA ZA UPRAVLJANJE PROJEKTIMA - ISTRAŽIVANJE UTICAJA NA ORGANIZACIONE I PROJEKTNE PERFORMANSE
}

\author{
PROJECT MANAGEMENT OFFICE - RESEARCH OF THE IMPACT ON \\ ORGANIZATIONAL AND PROJECT PERFORMANCE
}

\author{
Jovanka Rakić, Slobodan Morača Fakultet tehničkih nauka, Novi Sad
}

\begin{abstract}
Oblast - PROJEKTNI MENADŽMENT
Kratak sadržaj - Rad se bavi procesom upravljanja projektima usklađenim sa organizacionim ciljevima na strateškom nivou $i$ pozicioniranjem kancelarije za upravljanje projektima $u$ organizaciji. Rad se može sagledati iz dva dela. Teorijski deo predstavlja osnove upravljanja projektima $u$ kompanijama $i$ potrebu uspostavljanja organizacione jedinice za centralizovano upravljanje projektima (PMO). Opisane su uloge, funkcije $i$ modeli PMO, kao $i$ uslovi za njeno uspešno funkcionisanje. Praktični deo sadrži studiju slučaja organizacije koja je nedavno implementirala kancelariju za upravljanje projektima. Ovaj rad daje određen uvid $u$ načine utvrđivanja njene vrednosti.
\end{abstract}

Ključne reči: kancelarija za upravljanje projektima, PMO, projekat, program, portfelj, upravljanje projektima

Abstract - This paper deals with project management process aligned with organizational objectives on strategic level and positioning Project Management Office into organisation. The work could be considered in two parts. The theoretical part presents the basics of project management in companies and the need for the establishment of organizational unit for centralized project management (PMO). Roles, functions and models of PMO positioning in the companies are described as well as the conditions for its successful operation. The practical part contains a case study of an organization that recently implemented PMO. This paper provides some insight on ways to determine the value of a PMO.

Keywords: Project Management Office, PMO, project, program, portfolio, project management

\section{UVOD}

Uzimajući u obzir činjenicu da upravljanje raznovrsnim projektima, resursima (ljudima, opremom, tehnologijama, informacijama) i komunikacijom nije ni malo lak zadatak, a sa sobom nosi i veliki rizik od neuspeha, činjenica da se u svetu oko $70 \%$ projekata smatra neuspešnim, po kriterijumima Instituta za upravljanje projektima (PMI), nije uopšte iznenađujuca. Stanje je još drastičnije kada govorimo o IT projektima gde $74 \%$ od ukupnog broja propadne svake godine $\mathrm{i}$ da taj procenat $\mathrm{i}$ dalje raste.

Kao razlozi neuspeha pominju se probijanje vremenskih ograničenja i rokova, budžeta kao i neispunjenje ciljeva

\section{NAPOMENA:}

Ovaj rad proistekao je iz master rada čiji mentor je bio prof. dr Slobodan Morača. samog projekta. Uspostavljanje efektivnog i efikasnog organizacionog upravljanja projektima predstavlja dugoročan napor organizacije. Dodatno, da bi se ostvarile koristi koje su potrebne organizaciji, potreban je veliki broj organizacionih promena.

Od velike važnosti za uspešnu implementaciju i kontinuirani razvoj organizacionog upravljanja projektima je svakako i razumevanje koncepta kancelarije za upravljanje projektima - PMO (eng. Project Management Office PMO). PMO zauzima centralno mesto u organizaciji koje pruža neophodne informacije, podršku i postavlja standarde i procedure za izvođenje projekata u svim funkcionalnim jedinicama.

\section{POJAM I DEFINICIJE PMO}

PMO predstavlja uspešan okvir za upravljanje projektima, koristeci standardizovanu metodologiju, primenjujuci dobra iskustva u upravljanju projektima, obezbeđujuci da projekti budu u skladu sa korporativnim strateškim ciljevima i postavljajuci jasne granice odgovornosti za koordinaciju ljudskim resursima, procesima i alatima. $\mathrm{Na}$ taj način se izbegava nepokrivanje ili preklapanje poslova na različitim projektima, unapređuje se komunikacija unutar organizacije, smanjuju se troškovi projekata i poboljšavaju kvalitet i predviđanje planiranih vrednosti koji se odnose na realizaciju projekata [1]. Navedena teza predstavlja jedan od pokušaja definisanja kancelarije za upravljanje projektima. Međutim, vrlo je teško dati uopštenu i sveobuhvatnu definiciju, s obzirom da PMO formira i posmatra kao različit koncept $u$ skladu sa postojecim zahtevima, kulturom i naporima određene organizacije.

Rani primeri kancelarije za upravljanje projektima se javljaju još krajem 19. veka i vezani su unapređenje poljoprivrede u Velikoj Britaniji. Međutim, tek početkom 21. veka dolazi do ekspanzije poslovnih knjiga o PMO. Implementacija PMO pri razvoju softvera postaje veoma rasporostranjeno.

Kancelarija za upravljanje projektima se pojavljuje kao zasebna disciplina što kao rezultat ima prihvatanje, razvoj i opis kancelarije za upravljanje projektima u savremenoj literaturi. Menadžer projekata i PMO su evoluirali u odeljenje ili grupu unutar organizacije [2]. Važno je napomenuti da je PMO stalni deo organizacije, a ne privremeni napor ili autsorsovana (eng. out-sourced) aktivnost.

O njenoj značajnosti govori i činjenica da trenutno oko $70 \%$ korporacija u svetu ima PMO. 


\section{ULOGE I FUNKCIJE PMO}

Empirijska istraživanja su pokazala da PMO može imati veoma različite oblike koji se kreću u rasponu od pružanja administrativne podrške do preuzimanja direktne odgovornosti za upravljanje projektima, kada govorimo o ekspertskom centru na nivou cele organizacije.

Prilikom planiranja i uspostavljanju kancelarije za upravljanje projektima, imperativ i ključni napor je da se njegova struktura $i$ uloga $u$ potpunosti prilagode postojećoj strukturi organizacije, uzimajući u obzir činjenicu da je svaka organizacija drugačija.

$\mathrm{Na}$ ovaj način, ne samo da se obezbeđuje maksimalna efektivnost i korist od uspostavljanja PMO, vec se svaki drugi način uspostavljanja smatra izuzetno kontraproduktivnim.

U skladu sa prethodno pomenutim, kancelarija za upravljanje projektima može da ima četiri uloge. Administrativna kancelarija je vrsta informaciono administrativnog centra i ona sakuplja informacije koje su zajedničke za više projekata, vodi računa o stanju projekata i distribuira informacije zainteresovanim stranama. Centar izvrsnosti je primarno edukativnog karaktera $i$ ima ulogu za širenje dobre prakse među zaposlenima. Postavlja standarde koje je neophodno poštovati pri izvođenju projekata, stečena iskustva iz prethodnih projekata i praktično obučava rukovodioce projekata $i$ članove tima.

Kontrolna kancelarija ima ulogu da inicira i kontroliše projekte. Ovaj tip kancelarije obuhvata i prethodna dva u manjoj meri ali takođe više učestvuje u kontroli i moguće je da delegira rukovodica projekta za vreme trajanja projekta.

Izvršna kancelarija ima ulogu nadgledanja projekata tokom celokupnog životnog ciklusa i odgovorna je za celokupno planiranje i izvršavanje projekta, kao i delegiranje rukovodioca projekta $\mathrm{i}$ članove projektnog tima [3].

$\mathrm{S}$ druge strane, funkcije PMO variraju u zavisnosti od njene veličine i cilja same organizacije. Prema istraživanju PMI ukupno je identifikovano 27 različitih funkcija koje kancelarija za upravljanje projektima obavlja, grupisanih na razne načine. Najvažnijih 10 funkcija su:

- Izveštavanje višeg menadžmenta o projektima

- Razvoj i implementacija standarda i metodologija upravljanja projektima

- Praćenje i kontrola performansi projekata

- Razvoj kompetencija zaposlenih na polju upravljanja projektima, uključujući i obuke

- Implementacija i rad sa PMIS (Informacioni sistem za upravljanje projektima)

- Savetovanje top menadžmenta

- Koordinacija između projekata

- Razvoj i održavanje sistema za ocenu uspešnosti projekta (projektni Scoreboard)

- Promocija projektnog upravljanja u okviru organizacije

- Nadzor i kontrola perfomansi PMO [1].

\section{ISTRAŽIVANJE UTICAJA NA ORGANIZACIONE I PROJEKTNE PERFORMANSE}

Proces uvođenja PMO u organizaciju i njen razvoj predstavlja dugotrajan proces koji donosi jedinstvene izazove $\mathrm{i}$ probleme za svaku organizaciju. U nastavku je prikazan pokušaj sagledavanja uticaja PMO na projektne i organizacione performanse jednog realnog sistema, kao i identifikacija osnovnih izazova i problema s kojima se on susretao pre i posle uvođenja iste. Istraživanje je sprovedeno u kompaniji koja posluje na globalnom nivou, sa sedištem u Americi. Delatnost kompanije je vezana za rudarsku industriju. Kompanija je osnovala PMO 2012. godine, nakon velikih strukturalnih promena sa kojima se susrela.

\subsection{Hipoteze, metodologija i ciljevi istraživanja}

Metodologija istraživanja primenjena $u$ ovom radu jeste studija slučaja koja predstavlja intenzivno, dubinsko, detaljno proučavanje ili istraživanje pojedinačnog slučaja, gde je fokus na posebnostima. Jedna od polaznih pretpostavki bila je da se funkcije PMO-a mogu povezati sa vrednošcu koju PMO stvara u organizaciji.

Da bi se to postiglo predložen je konceptualni model na slici 1. Model započinje sa funkcijama za koje je PMO zadužen (1).

Ove funkcije imaju određene efekte na organizaciju i njene projekte (2).

Stvoreni efekti dodaju novu vrednost (3).

Ova vrednost može biti pozitivna ili negativna. Dodata vrednost od strane PMO uticaće na performanse projekta i organizacije. Upoređivanjem projektnog okruženja pre implementacije PMO-a sa projektnim okruženjem nakon implementacije PMO-a, bice evidentirane uočene promene, čijom analizom se mogu se utvrditi efekti PMO (4) [4].

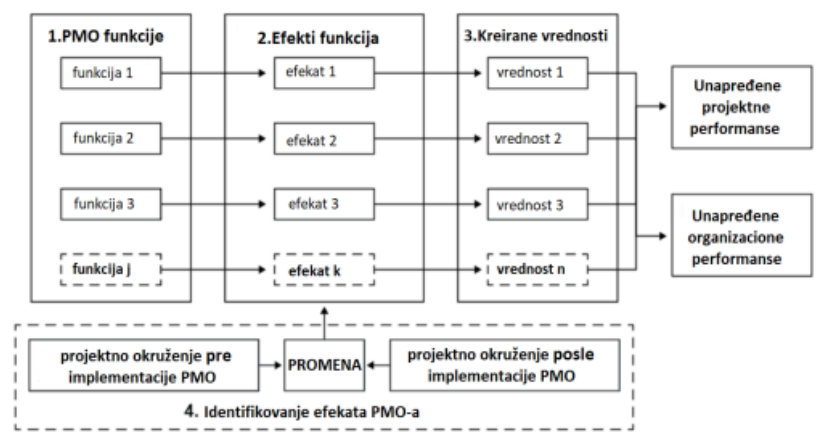

Slika 1. Konceptualni model uticaja funkcija PMO

Cilj istraživanja je da se na jasan i sistematičan način predstavi celokupan efekat PMO na organizacione $i$ projektne performanse, proučavanjem svih pojedinačnih uticaja koji se ostvaruju kroz pojedine funkcije PMO-a. Na osnovu rezultata istraživanja moguće je utvrditi koji su značajni faktori uspeha PMO i moguća područja unapređenja poslovanja organizacije u budućnosti.

\subsection{Rezultati istraživanja}

Prva grupa pitanja na koje je tražen odgovor odnosila se na razloge uvođenja PMO u organizaciju. Kao posledica većih strukturalnih promena i nedostatka metodologija koje bi obezbedile efikasno i uspešno upravljanje projektima, javili su se problemi koji su se prvenstveno odnosili na nedostatak standarda i smernica za upravljanje 
projektima koji se mogu dosledno koristiti na svim organizacionim nivoima.

Takođe, pomenuta je loša raspedela resursa, nepostojanje centralizovanog i konzistentnog modela izveštavanja o upravljanju, kao i nedostatak obuka i mentorstva. Druga grupa pitanja imala je za cilj da identifikuje funkcije koje PMO obavlja u kompaniji. Na osnovu dobijenih rezultata je utvrđeno da ne postoji veliki raskorak između onoga što je definisano dokumentacijom kompanije prilikom pokretanja PMO, od onoga šta PMO obavlja u praksi.

Funkcije u nadležnosti PMO uključuju pokretanje, primena i održavanje sistema Enterprise Project Management (EPM), obezbeđivanje tačne i pravovremene dostupnosti informacija, kao i ,vidljivosti projekta“, pružanje podrške menadžerima programa i projekata u obliku kontrole dokumenata i upravljanja znanjem, kontrole troškova projekta, koordinacije resursa, planiranja projektih aktivnosti, upravljanja rizikom i administracijom.. Takođe, sprovodi se obuka rukovodilaca programa i projekata i projektnih timova vezano za metodologiju i određena područja znanja upravljanja projektima.

Naredna grupa pitanja se odnosila na identifikovane efekte koje PMO ostvaruje na organizaciju. Jedan od efekata koji PMO ima na organizaciju je da povećava nivo zrelosti upravljanja projektima. Da bi se utvrdio kakav efekat ovaj konkretan PMO ostvaruje na predmetnu organizaciju, korišćen je Model zrelosti organizacionog upravljanja projektima, tzv. Project Management Institute's (PMI) Organizational Project Management Maturity Model ili skraćeno OPM3®, kako bi se odredila zrelost upravljanja projektima pre i posle implementacije PMO [5].

$\mathrm{Na}$ osnovu detaljne analize svih prikupljenih podataka, može se zaključiti da je PMO dramatično uticao na zrelost organizacije u pogledu upravljanje projektima. Na osnovu poređenja OPM3 ${ }^{\circledR}$ anketa koje su rađene u 2010. godini (pre uspostavljanja PMO) i u 2014. godine (nakon uspostavljanja PMO), ukupna zrelost organizacionog upravljanja povecana je sa $22 \%$ na $44 \%$, dok se zrelost upravljanja projektima povećala sa $24 \%$ na $69 \%$. Ostvareno je svih trideset devet najboljih praksi upravljanja projektima, u poređenju sa samo četiri u 2010. godini. Zrelost upravljanja programima je povećana sa $0 \%$ na $22 \%$, a upravljanja portfeljem sa $10 \%$ na $18 \%$.

Ključni pokazatelj performansi (KPI) koji se koristi za merenje performansi portfelja projekata ove kompanije je tačnost kapitalnog trošenja. To je stvarni kapitalni izdatak izražen kao procenat od budžeta planiranog za određenu godinu. Ovaj KPI pokazao je značajno poboljšanje od primene PMO. Poboljšao se sa prosečno $50 \%$ na $81 \%$ u godini kada je PMO osnovan. Sledeće godine je postignuto $90 \%$ tačnosti potrošnje. Poboljšanje ovog KPI ukazuje na poboljšanu sposobnost kompanije da izvršava svoje projekte [4].

Takođe, utvrđeno je da je uspostavljanje PMO imalo je i nekoliko negativnih uticaja. Najveći negativni uticaj se odnosio na povećanje troškova koji se raspoređuju se na pojedinačne projekte kako bi na taj način mogli biti naplaćeni, s obzirom da kompanija nije prethodno imala obezbeđen budžet u ove svrhe. Dodeljeni dodatni troškovi upravljanja projektom svaki projekat, a posebno one manjeg obima, čine manje ekonomski održivim. Drugi problem na koji se naišlo, i koji traje dve godine nakon primene, jeste otpor prema promenama. Nova metodologija, procedure i pravila nisu lako usvojene. Pojedine tenzije i sukobi između departmana su direktno uzrokovani novim načinom rada koji je sa sobom donela kancelarija za upravljanje projektima.

Upoređujući probleme koji su se susreli pre uvođenja kancelarije za upravljanje projektima i probleme koji su stvarno rešeni, jasno je da PMO ispunjava svoju svrhu. Opšti konsenzus među ispitanicima takođe je potvrdio da PMO ispunjava svoju svrhu, ali i da još uvek nije dostigla svoj puni potencijal. Kao razlozi za to navode se sledeci:

- PMO još uvek nema dovoljno osoblja;

- nivo obučenosti PMO osoblja još uvek nije na nivou standarda;

- kriterijumi uspeha PMO nisu još uvek precizno definisani;

- PMO ne razume kulturu organizacije u potpunosti;

- nisu dostupne sve funkcije podrške jer je PMO još uvek u fazi rasta, a otpor promenama ometa napredak;

- pojedinci i dalje žude za bivšim položajima ili statusima pre primene PMO-a [6].

\subsection{Povezivanje funkcija PMO sa ostvarenim vrednostima}

Odgovaranjem na istraživačka pitanja, mogu se popuniti različita polja na prethodno prikazanom konceptualnom modelu za povezivanje funkcija PMO sa ostvarenim vrednostima. Prikazivanje rezultata istraživanja u ovom formatu pokazuje vrednost svake funkcije. Međutim, neophodno je razumeti da nijedna funkcija ne može zaista dodati vrednost izolovano od ostalih funkcija. Na primer, alati i sistemi će biti beskorisni ukoliko se ne kombinuju sa metodologijama ili funkcijama podrške za pokretanje ovog sistema. Slično tome, metodologije ne mogu dodavati vrednost bez sistema i funkcija podrške projektima koje bi podržale njegovu implementaciju. Svaka funkcija sama po sebi može dodati vrednost, ali prava vrednost PMO-a leži u sinergiji između funkcija [7].

U ovom konkretnom slučaju, poboljšanje tačnosti kapitalne potrošnje nije rezultat jedne posebne funkcije. Upravo je sinergija svih funkcija doprinela ovoj vrednosti. Prethodni konceptualni model se može revidirati da bi se pokazalo da su ostvarene vrednosti rezultat kombinacije svih funkcija kao što je prikazano u nastavku [4].

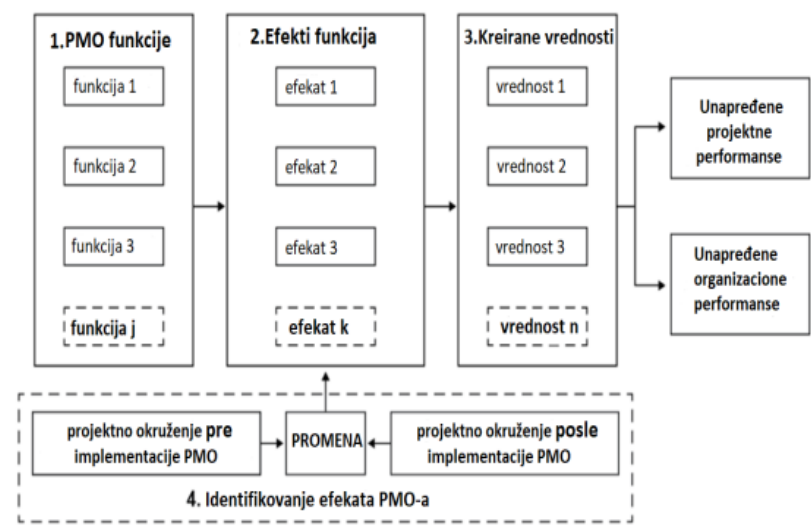

Slika 2: Revidirani konceptualni model povezivanja funcija i vrednosti PMO 


\section{ZAKLJUČNA RAZMATRANJA}

Efikasno upravljanje projektima je od suštinske važnosti za opstanak i razvoj većine organizacija. One organizacije koje ostvaruju najveću vrednost u upravljanju svojim projektima su one koje imaju konzistentne, podržane i relevantne prakse upravljanja projektima. Shodno tome, cilj je da se neprestano radi na njihovom razvijanju i unapređenju. Stvaranje i podržavanje ovakve prakse je svakako jedna od glavnih uloga kancelarije za upravljanje projektima. Naravno, na tome se mora raditi, i taj proces mora biti kontinualan. Načini se razlikuju od organizacije do organizacije, i mnogo je faktora na koje se mora obratiti pažnja. Međutim, preduslovi za uspešnu implementaciju sistema poslovanja koji donosi PMO i upravljanje projektima jeste adekvatna organizaciona kultura i podrška izvršnog menadžmenta [8].

Uvođenjem kancelarije za upravljanje projektima, kompanije čine jedan veliki korak ka unapređenju sopstvenog poslovanja. Međutim, to je samo prvi korak u procesu koji mora biti kontinualan. Buduće odluke i akcije moraju biti u duhu konstantnog razvoja kompetencije funkcije upravljanja projektima i sticanja projektne zrelosti. Na taj način ce se povecati potencijal za postizanje boljih poslovnih rezultata.

Kako bi kancelarija za upravljanje projektima bila uspešna i opstala u svom radu:

- mora imati veliku podršku top menadžmenta,

- mora biti dobro pozicionirana u organizaciji,

- mora biti sačinjena od osoba sa iskustvom $\mathrm{i}$ ekspertizom sa primenom najnovijih standarda i praksi,

- njeni članovi se moraju konstantno usavršavati i donositi nova znanja i veštine i dispergovati ih na celu organizaciju. Ti članovi moraju biti vizionari i implementatori promena.

Takođe je neophodno imati na umu da da je kancelarija za upravljanje projektima jedinstvena, jer služi jedinstvenim potrebama konkretne organizacije. Potrebno je da bude perfektno skrojena prema organizaciji kako bi podržala njenu strategiju i zaposlene. Jedan model i način rada ne znači da ce dati iste rezultate $u$ drugoj organizaciji.

U današnjim uslovima poslovanja, sve referentne kompanije sa značajnim investicijama imaju kancelariju za upravljanje projektima. U poslovnom svetu više niko ne postavlja pitanje: „Da li nam treba PMO?“, već: „Kakva uloga/funkcija PMO odgovara potrebama naše kompanije?“ i „Kakva je optimalna organizaciona pozicija PMO u našoj kompaniji?“،.

\section{LITERATURA}

[1] D. Grbovic, M. Avramovic, P. Radoševic, M. Opsenica, M. Đonovic, M. Božic, Upravljanje projektima i uloga biroa za upravljanje projektima i programima u telekomunikacionim kompanijama, Telekom Srbija a.d., 2014.

[2] G. I. Kendall, S. C. Rollins, Advanced Project Portfolio Management and the PMO, International Institute for Learning, Inc. and J. Ross Publishing, Inc., 2003.

[3] V. Todorovic, D. Nikolic, F. Kulic, O. Đuričic, M. Jovanovic, Uloga kancelarije za upravljanje projektima na Fakultetu tehničkih nauka, Univerzitet u Novom Sadu, Fakultet tehničkih nauka, Novi Sad, Republika Srbija, 2013.

[4] H. Steyn, J. van der Linde, The effect of a Project Management Office on project and organisational performance: A case study, Department of Engineering and Technology Management, Graduate School of Technology Management, University of Pretoria, Soutt Africa, 2016.

[5] Project Management Institute, "Organizational Procet Management Maturity Model (OPM3) - Second Edition“, 2012.

[6] B. Hobbs, M. Aubry, A multi-phase research program investigating project management offices: The results of phase 1, Project Management Journal, 38 (1), pp. 74-86., 2007.

[7] M. Aubry, B. Hobbs, D. Thuillier, A new framework for understanding organizational project management through the PMO, International Journal of Project Management, 25 (4), pp. 328-336., 2007.

[8] M. L. Young, "Key steps to implement a project management office". [Online]. Available:

https://www.projectsmart.co.uk/key-steps-to implement-aproject-management-office.php. [Accessed 09 2019].

\section{Kratka biografija}

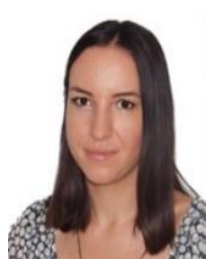

Jovanka Rakić rođena je u Bačkoj Topoli 1993. godine. Master rad na Fakultetu tehničkih nauka iz oblasti Industrijskog inženjerstva i inženjerskog menadžmenta - Projektni menadžment odbranila je 2019. god. Trenutno je zaposlena na poziciji Junior Project Manager u okviru Kancelarije za upravljanje projektima u IT firmi u Novom Sadu. 